\title{
A FORMAÇÃO PIRAÇUNUNGA NA REGIÃO \\ DE VARGEM GRANDE DO SUL, SP. APLICAÇÃO DA TÉCNICA DE PERFIS SEDIMENTARES
}

\author{
Ruy Osório de FREITAS \\ Percy Corrêa VIEIRA \\ Sérgio MEZZALIRA
}

\section{RESUMO}

Neste trabalho, com base nos processos do Sedimentograma e dos Perfis Sedimentares (este aqui introduzido), foi feito um estudo da Formação Piraçununga na Folha de São João da Boa Vista, com a proposição informal da fácies Vargem Grande do Sul para a porção psamopelítica a sudoeste daquela cidade, interpretada como sedimentada em pianícies de inundação, com possibilidade de contribuição tectônica. Para o restante da unidade deu-se o nome informal de fácies Leme, que apresenta um caráter granulométrico mais grosso e sedimentação em ambiente mais enérgico. Com base no conteúdo paleontológico (vegetal e inseto) é sugerida uma idade oligomiocênica para a fácies Vargem Grande do Sul, que pode, com restrições, ser estendida a toda a Formação Piraçununga, ou apenas ao início dela, por tratar-se a fácies em questão de deposição sincrônica com o restante ou, pelo menos, com a parte basal.

\section{ABSTRACT}

The informal name of Vargem Grande do Sul is here proposed for the psamopelitic lithofacies of the supposed Oligocene-Miocene Piraçununga Formation outcropping in the São João da Boa Vista area. This facies is interpreted as an alluvial plain deposit probably related to fault tectonism. A new unit, the Leme facies, is also proposed for the coarser sediments of the Piraçununga Formation - laid down at the same time or later as a higher level.

Based on plant and insect fossils, Oligocene-Miocene age is attributed to the Vargem Grande do Sul facies in the lower part of the formation. This age cannot surely be generalized for the whole formation.

\section{INTRODUÇÃO}

Um dos grandes problemas da Formação Piraçununga (FREITAS et al., 1979) tem sido o estabelecimento exato da cronologia de sua deposição, devido à natureza predominantemente afossilífera, naturalmente realçada pela característica grosseira dos seus sedimentos, denunciando ambientes de deposição não propícios à fossilização. Todavia, os sedimentos argilosos, contendo folhas de vegetais a sudoeste de Vargem Grande do Sul, abrem caminho paleontológico para datação do evento sedimentar.

O objetivo deste trabalho é estudar litológica e biologicamente essa fácies predominantemente pelítica, existente na Fazenda Cachoeirinha, naquela região, que tem uma área apro- ximada de quinze quilômetros quadrados e mostrada na Folha Geológica de São João da Boa Vista (INSTITUTO GEOLÓGICO, 1982).

Esses estudos permitiram-nos propor a designação informal de fácies Vargem Grande do Sul para esses sedimentos argilosos e fossilíferos dentro da Formação Piraçununga e sugerir tentativamente uma datação oligomiocênica para o evento sedimentar.

\section{ESTUDO GRANULOMÉTRICO}

\subsection{Material}

Para o estudo granulométrico foram tratadas vinte e duas amostras da Formação Piraçununga na Folha de São João da Boa Vista, na escala de 1:50000 (SF-23-V-C-VI-3), com as seguintes coordenadas UTM: 


\begin{tabular}{llcccccc}
\multicolumn{2}{c}{ Amostra } & \multicolumn{2}{c}{ Coordenadas } & \multicolumn{2}{c}{ Amostra } & \multicolumn{2}{c}{ Coordenadas } \\
& & X & Y & & \multicolumn{2}{c}{ Y } \\
SJ 054 & 2995 & 75724 & SJ & 120 & 2967 & 75791 \\
SJ 060 & 2993 & 75745 & TSJ & 005 & 2982 & 75740 \\
SJ 062 & 2998 & 75773 & TSJ & 008 & 2945 & 75861 \\
SJ 067 & 3038 & 75817 & TSJ & 010 & 2944 & 75796 \\
SJ 068 B & 3042 & 75819 & TSJ & 011 & 3031 & 75829 \\
SJ 068 C & 3042 & 75819 & VGS & 001 A & 3042 & 75819 \\
SJ 077 & 2952 & 75801 & VGS & 001 B & 3042 & 75819 \\
SJ 080 & 2947 & 75851 & VGS & 002 & 3042 & 75819 \\
SJ 081 & 2962 & 75896 & VGS 003 & 3042 & 75819 \\
SJ 085 & 2952 & 75736 & VGS & 004 & 3042 & 75819 \\
SJ 114 & 2943 & 75699 & VGS 005 & 3042 & 75819
\end{tabular}

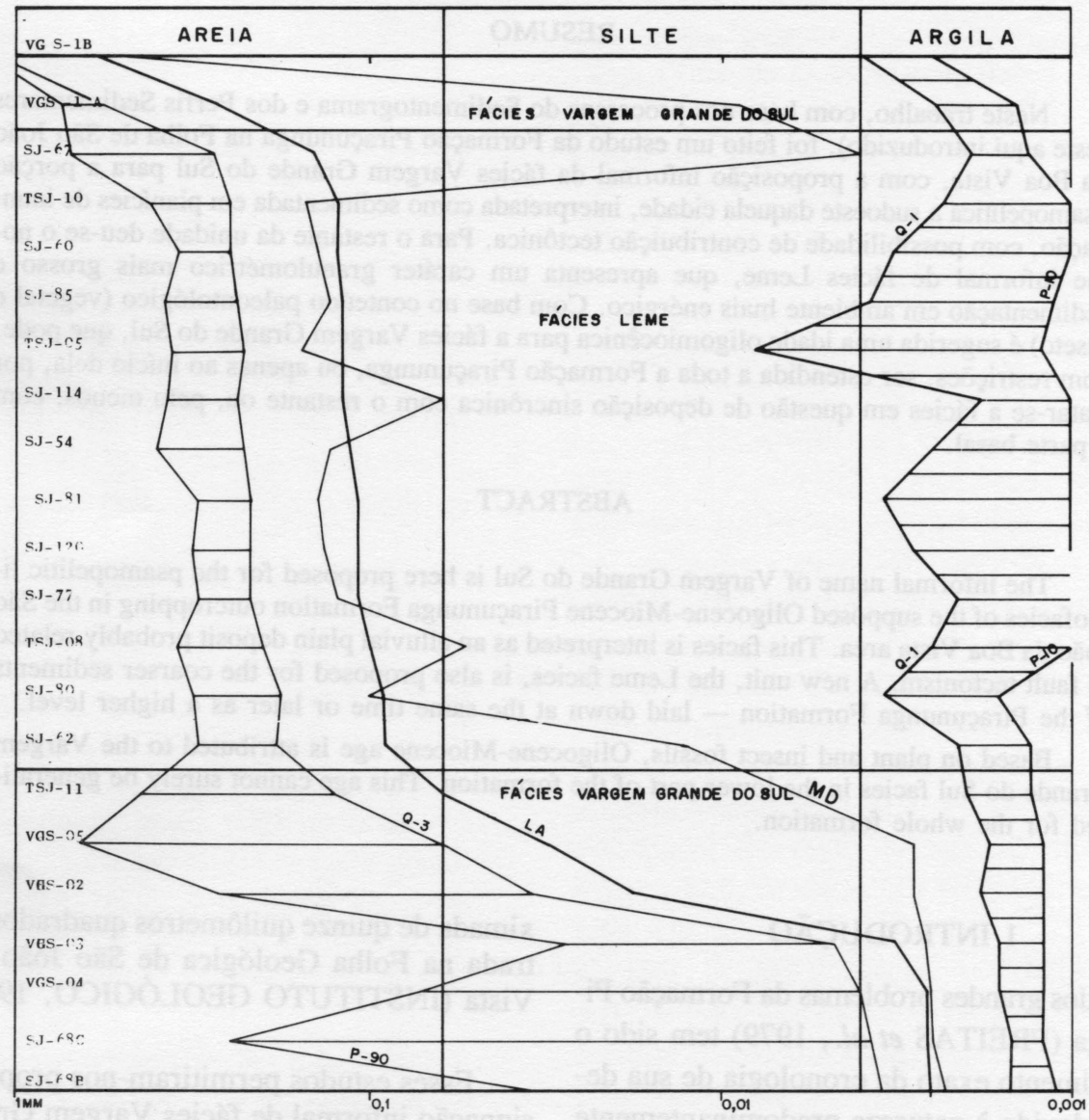

GRÁFICO 1 - Sendimentograma. Relações entre os parâmetros granulométricos em amostras da Formação Piraçununga na Folha de São João da Boa Vista.

As amostras TSJ correspondem a furos a trado nas respectivas profundidades: TSJ 005 , TSJ 008 e TSJ 010 - 2 a 4 metros; TSJ 011 - 4 a 8 metros. As amostras VGS, bem como as SJ 068 B e C, foram coletadas na antiga mineração da Fazenda Cachoeirinha.

\subsection{Métodos}

Procedeu-se à pipetagem e ao peneiramento das amostras, com construção das curvas gra- nulométricas acumulativas, das quais se obtiveram os parâmetros constantes da Tabela Textural e Estatística, para a feitura do sedimentograma e dos perfis sedimentares.

\subsubsection{Granulometria}

Considerando-se que, por conceituação, uma litofácies deve ter homogeneidade física na ver- 


\begin{tabular}{|c|c|c|c|c|c|c|c|c|c|c|c|c|c|c|}
\hline \multirow{2}{*}{ AMOSTRAS } & \multirow{2}{*}{ 这 } & \multirow{2}{*}{ 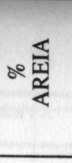 } & \multirow{2}{*}{ of } & \multirow{2}{*}{ 얼 } & \multirow{2}{*}{$\begin{array}{l}\mathrm{P}-90 \\
\mathrm{~mm}\end{array}$} & \multirow{2}{*}{$\begin{array}{l}\text { Q-3 } \\
\mathrm{mm}\end{array}$} & \multirow{2}{*}{$\begin{array}{c}\text { MD } \\
\text { NA } \\
\text { FRÇÃO } \\
\text { GROSSA } \\
\text { mm } \\
\end{array}$} & \multicolumn{2}{|c|}{$\begin{array}{l}\text { LIMITE DAS } \\
\text { ADMISTURAS }\end{array}$} & \multirow{2}{*}{$\begin{array}{c}\text { MD } \\
\text { NA } \\
\text { FRAÇÃO } \\
\text { FINA } \\
\text { mm } \\
\end{array}$} & \multirow{2}{*}{$\begin{array}{l}\mathrm{Q}-\mathrm{I} \\
\mathrm{mm}\end{array}$} & \multirow{2}{*}{$\begin{array}{l}P-10 \\
\mathrm{~mm}\end{array}$} & \multirow{2}{*}{$\begin{array}{c}\text { CLASSE MODAL } \\
\begin{array}{c}\text { DIÂMETROS } \\
\mathrm{mm}\end{array}\end{array}$} & \multirow{2}{*}{ 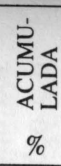 } \\
\hline & & & & & & & & $\begin{array}{c}\text { DIÂMETROS } \\
\mathrm{mm}\end{array}$ & $\begin{array}{c}\% \\
\text { ACUMULADA }\end{array}$ & & & & & \\
\hline SJ - 68 B & - & 07 & 10 & 83 & 0,031 & 0,0035 & - & 0,0025 & 45 & 0,0023 & 0,0015 & 0,0011 & $<0,004$ & 84 \\
\hline SJ - $68 \mathrm{C}$ & - & 15 & 05 & 80 & 0,250 & 0,0037 & - & 0,0026 & 46 & 0,0025 & 0,0015 & 0,0010 & $<0,004$ & 80 \\
\hline VGS - 04 & - & 15 & 10 & 75 & 0,070 & 0,0040 & - & 0,0028 & 44 & 0,0025 & 0,0016 & 0,0012 & $<0,004$ & 75 \\
\hline VGS - 03 & - & 04 & 23 & 73 & 0,027 & 0,0048 & - & 0,0032 & 40 & 0,0026 & 0,0016 & 0,0012 & $<0,004$ & 73 \\
\hline VGS - 02 & - & 20 & 13 & 67 & 0,270 & 0,0350 & - & 0,0184 & 27 & 0,0028 & 0,0018 & 0,0012 & $<0,004$ & 67 \\
\hline VGS - 05 & - & 25 & 07 & 68 & 0,580 & 0,0620 & - & 0,0318 & 27 & 0,0028 & 0,0017 & 0,0012 & $<0,004$ & 66 \\
\hline TSJ - 11 & - & 31 & 21 & 48 & 0,450 & 0,1250 & - & 0,0635 & 30 & 0,0060 & 0,0020 & 0,0013 & $<0,004$ & 48 \\
\hline SJ - 62 & - & 47 & 09 & 44 & 0,310 & 0,1850 & - & 0,0935 & 43 & 0,0130 & 0,0021 & 0,0013 & $0,177-0,125$ & 38 \\
\hline SJ - 80 & - & 59 & 13 & 28 & 0,320 & 0,1800 & 0,100 & 0,0917 & 53 & - & 0,0034 & 0,0016 & $0,177-0,125$ & 42 \\
\hline TSJ - 08 & - & 49 & 12 & 39 & 0,350 & 0,1800 & - & 0,0910 & 45 & 0,0620 & 0,0020 & 0,0009 & $0,250-0,177$ & 30 \\
\hline SJ - 77 & - & 59 & 06 & 35 & 0,310 & 0,2200 & 0,125 & 0,1110 & 52 & - & 0,0021 & 0,0009 & $0,250-0,177$ & 36 \\
\hline SJ - 120 & - & 62 & 08 & 30 & 0,320 & 0,2200 & 0,135 & 0,1114 & 56 & - & 0,0028 & 0,0010 & $0,250-0,177$ & 39 \\
\hline SJ - 81 & - & 63 & 09 & 28 & 0,310 & 0,2200 & 0,140 & 0,1117 & 58 & - & 0,0034 & 0,0010 & $0,250-0,177$ & 39 \\
\hline SJ - 54 & - & 61 & 08 & 31 & 0,410 & 0,2300 & 0,130 & 0,1162 & 54 & - & 0,0025 & 0,0009 & $0,177-0,125$ & 52 \\
\hline SJ - 114 & - & 50 & 09 & 41 & 0380 & 0,2400 & - & 0,1209 & 46 & 0,0620 & 0,0018 & 0,0009 & $0,250-0,177$ & 38 \\
\hline TSJ - 05 & - & 68 & 07 & 25 & 0,370 & 0,2300 & 0,155 & 0,1190 & 58 & - & 0,0080 & 0,0012 & $0,354-0250$ & 29 \\
\hline SJ - 85 & - & 68 & 06 & 26 & 0,380 & 0,2400 & 0,130 & 0,1218 & 53 & - & 0,0037 & 0,0011 & $0,250-0,177$ & 39 \\
\hline SJ - 60 & - & 67 & 05 & 28 & 0,350 & 0,2500 & 0,140 & 0,1266 & 54 & - & 0,0032 & 0,0010 & $0,250-0,177$ & 41 \\
\hline TSJ - 10 & - & 61 & 05 & 34 & 0,420 & 0,2500 & 0,148 & 0,1261 & 57 & - & 0,0023 & 0,0009 & $0,250-0,177$ & 44 \\
\hline SJ -67 & - & 40 & 10 & 50 & 0,700 & 0,2800 & - & 0,1409 & 34 & 0,0040 & 0,0019 & 0,0013 & $<0,004$ & 49 \\
\hline VGS - O1A & - & 54 & 07 & 39 & 0,740 & 0,5400 & - & 0,2712 & 40 & 0,0888 & 0,0024 & 0,0014 & $1,000-0,707$ & 21 \\
\hline VGS - O1B & 09 & 58 & 08 & 25 & 1,900 & 1,2000 & - & 0,6020 & 49 & 0,5800 & 0,0040 & 0,0025 & $1,000-0,707$ & 46 \\
\hline
\end{tabular}

w TABELA TEXTURAL E ESTATÍSTICA - Parâmetros granulométricos e da composição em amostras da Formação Piraçununga na Folha de São João da Boa Vista. 
tical (espessura) e na horizontal (área), chega-se à conclusão de que esta uniformidade litológica depende essencialmente da granulação (para as unidades detríticas), como também das estruturas sedimentares, do conteúdo mineralógico leve e pesado etc. Métodos sedimentológicos emanados da análise mecânica e estatística dos sedimentos clásticos são os mais indicados para caracterizar uma unidade dessa origem.

Com o escopo de visualizar em gráficos objetivos as características sedimentológicas de uma formação através de sua granulometria, FREITAS (1973) apud FREITAS (1982) criou o Sedimentograma, que vem a ser um espectro linear da granulometria (expressa em milímetros) na abcissa e em uma seqüência de amostras na ordenada. Assim, pode-se ter uma idéia da variação granulométrica de uma dada formação. As discrepâncias são o resultado de uma outra fácies ou mesmo de outra formação, fato que deve ser resolvido às custas da geologia de campo.

Neste trabalho é apresentado novo processo de definição de uma formação, chamado de Perfis Sedimentares, amparado em dados da Tabela Textural e Estatística, construída com base na análise estatística das curvas acumulativas confeccionadas com os elementos fornecidos pela análise mecânica dos sedimentos clásticos.
O elemento estatístico mais importante como critério institucional de uma formação é o Limite das Admisturas (L.A.), concebido por UDDEN (1914), ou seja, a média aritmética dos quartéis. Essa grandeza representa o critério definidor de uma formação, pois deve admitir uma ligeira amplitude de variação granulométrica, caracterizando a formação. Os dados são expressos sempre em percentagem acumulada.

Na confecção da Tabela Textural e Estatística, para cada amostra, são obtidos nas curvas acumulativas os percentuais das classes texturais, P-90 (diâmetro no qual 10\% da amostra, em massa, são mais grossos e $90 \%$ mais finos do que ele), Q-3, Md, L.A., Q-1, P-10 (diâmetro no qual $90 \%$ da amostra, em massa, são mais grossos e $10 \%$ mais finos do que ele), a classe modal principal e sua percentagem acumulada.

\subsubsection{Sedimentograma}

O Sedimentograma (Gráfico 1) exprime a granulometria absoluta em milímetros de uma seqüência de amostras, bem como as relações entre P-90, Q-3, Md(Mediana), Q-1 e P-10, devido às expansões variáveis de tamanho existentes entre eles.

Uma fácies qualquer é representada por uma pequena variação de tamanho do Limite das Admisturas (L.A.). Quando aparecem variações

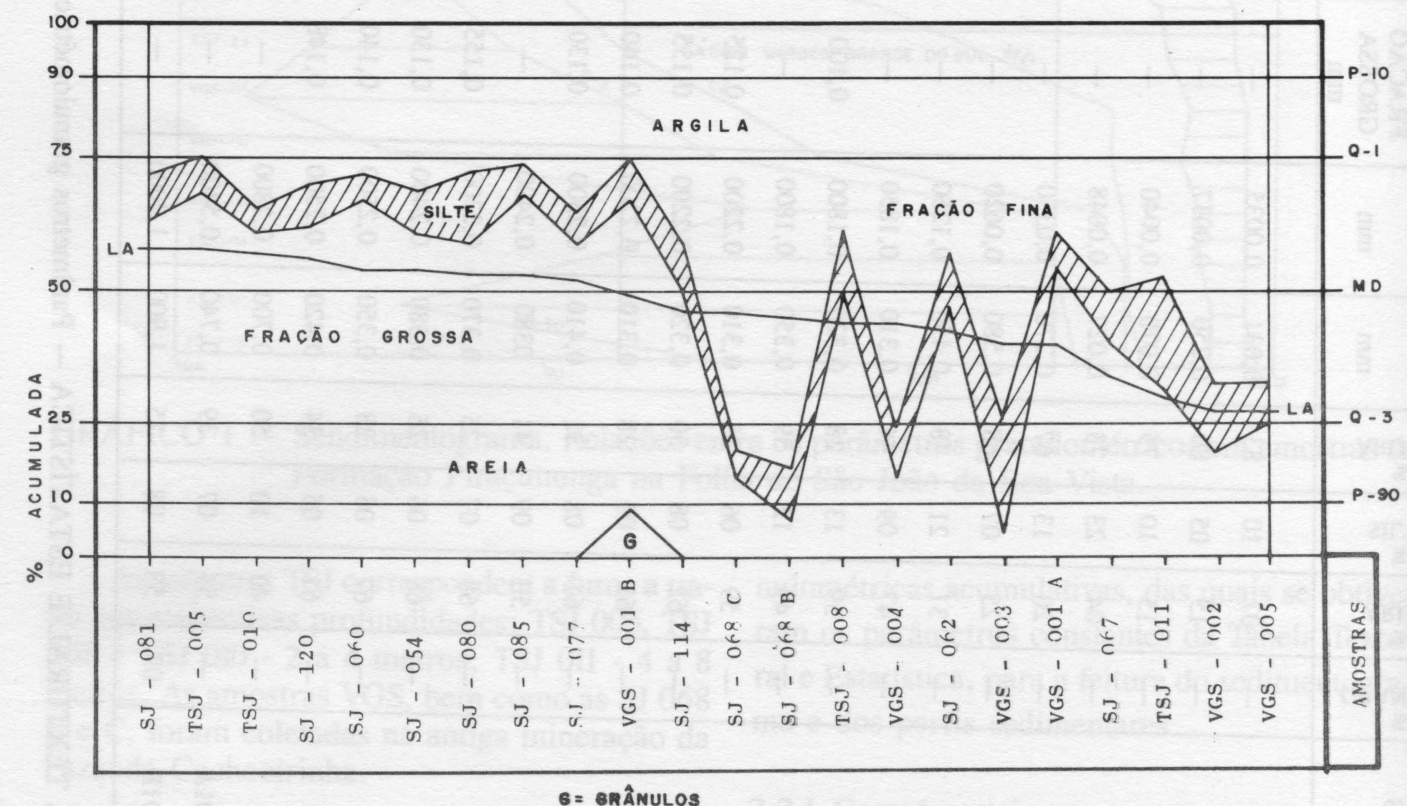

GRÁFICO 2 - Perfil Sedimentar Deposicional. Variação da energia no meio da deposição em amostras da Formação Piraçununga na Folha de São João da Boa Vista. 
grandes de L.A., tal fato exprime a presença de outra fácies ou de outra formação, dependendo da constatação de uma discordância entre ambas em seqüências visíveis no campo.

A mediana, postando-se à esquerda do limite das admisturas, indica que a fração grossa é maior do que a fina. Este fato caracteriza uma perda lenta de energia do veículo no sítio da sedimentação, de modo que a parte fina permanece em suspensão em boa parte. Quando a mediana fica à direita do limite das admisturas a perda de energia do veículo é relativamente rápida no sítio da deposição.

O Sedimentograma também exprime as variações texturais de uma seqüência de amostras, bem como em que textura posicionam-se os valores estatísticos como P-90, Q-3, Md, L.A., Q-1 e P-10 que, em uma dada formação clástica, são uniformes.

\subsubsection{Perfis Sedimentares}

Os perfis sedimentares são gráficos de três tipos, construídos com a freqüência acumulada recaída: $1^{\circ}-$ nos valores do limite das admisturas (Perfil Sedimentar Deposicional), ${ }^{\circ} \mathbf{0}-$ nas texturas areia, silte e argila (Perfil Sedimentar Textural) e $3{ }^{\circ}-$ no posicionamento em modas segundo suas classes de tamanhos (Perfil Sedimentar da Carga), todos representados nas ordenadas, sendo que nas abcissas fica a seqüência desses valores em ordem decrescente para a direita. Consistem na relação entre suprimento e acumulação, sendo que o suprimento depende da velocidade de erosão na fonte, enquanto que a acumulação nem sempre é diretamente propor- cional ao suprimento. É comum um abundante suprimento resultar em pequena acumulação porque o sítio de deposição permite que grande parte desse material seja carreado para além.

\subsubsection{Perfil Sedimentar Deposicional}

O Perfil Sedimentar Deposicional é construído para mostrar o perfil energético do meio da sedimentação. O tamanho do limite das admisturas passa a ser expresso pela sua deposição na escala de freqüência acumulada, em ordem decrescente para a direita, no eixo das ordenadas. A seguir são pontuados os valores dos teores de areia, silte e argila, com sua correspondência em percentagem acumulada, de acordo com a Tabela Textural e Estatística, também nas ordenadas. Os valores de L.A. decrescem para a direita, enquanto que os valores de P-90, Q-3, Md, Q-1 e P-10 são lineares respectivamente a 10, 25, 50, 75 e $90 \%$ ao longo da ordenada (Gráfico 2).

De pronto verifica-se que a linha quebrada descendente de L.A. fica em parte acima da mediana (percentagem acumulada superior a $50 \%$ ) e em parte abaixo (percentagem acumulada inferior a $50 \%$ ). No primeiro caso a fração grossa é maior do que a fina e portanto a mediana repousa nela, o que indica que o veículo no sítio de depositação perdia lentamente a energia, facilitando a remoção das texturas finas, em suspensão, para além. No segundo caso a fração fina é maior, estando L.A. abaixo da mediana, o que dá a posição da mediana na fração fina. Este fato significa que a perda de energia do veículo no sítio de deposição foi relativamente rápida para permitir a decantação da parte fina em maior quantidade do que a grossa.

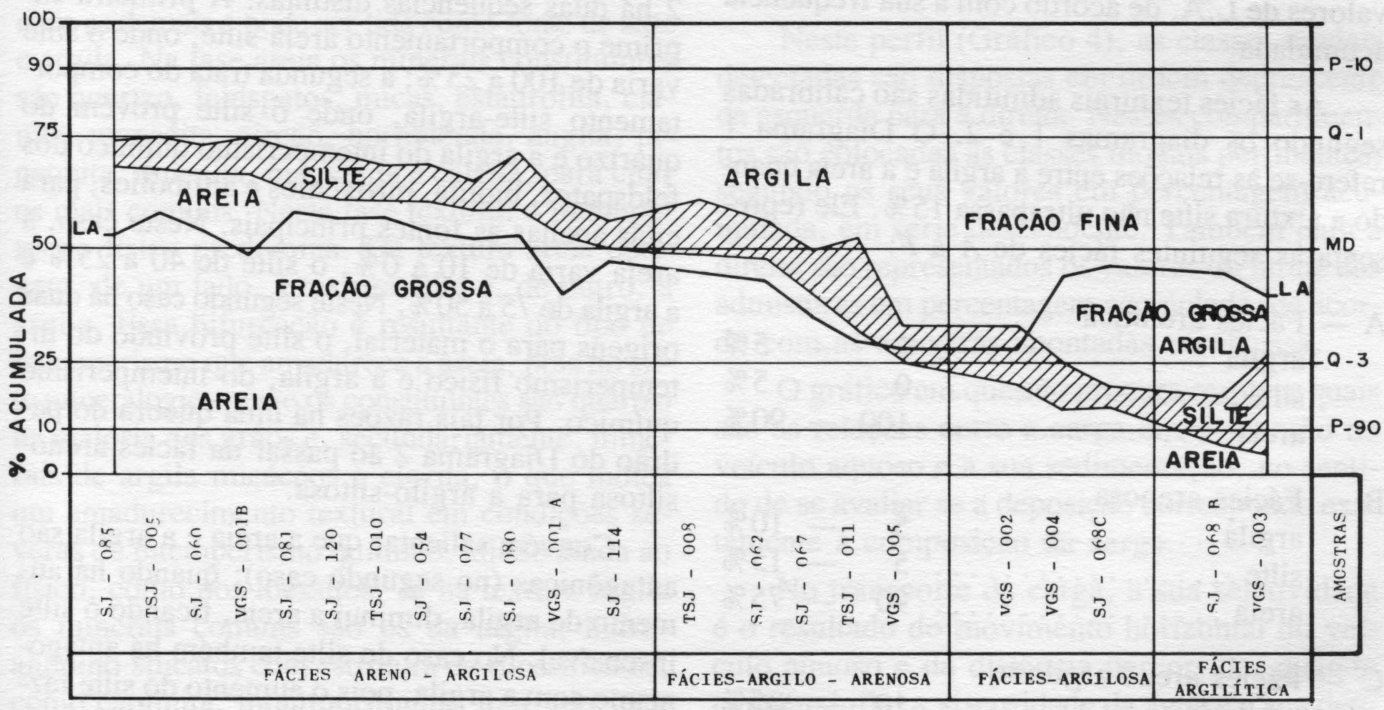

GRÁFICO 3 - Perfil Sedimentar Textural. Distribuição quantitativa das texturas em amostras da Formação Piraçununga na Folha de São João da Boa Vista. 


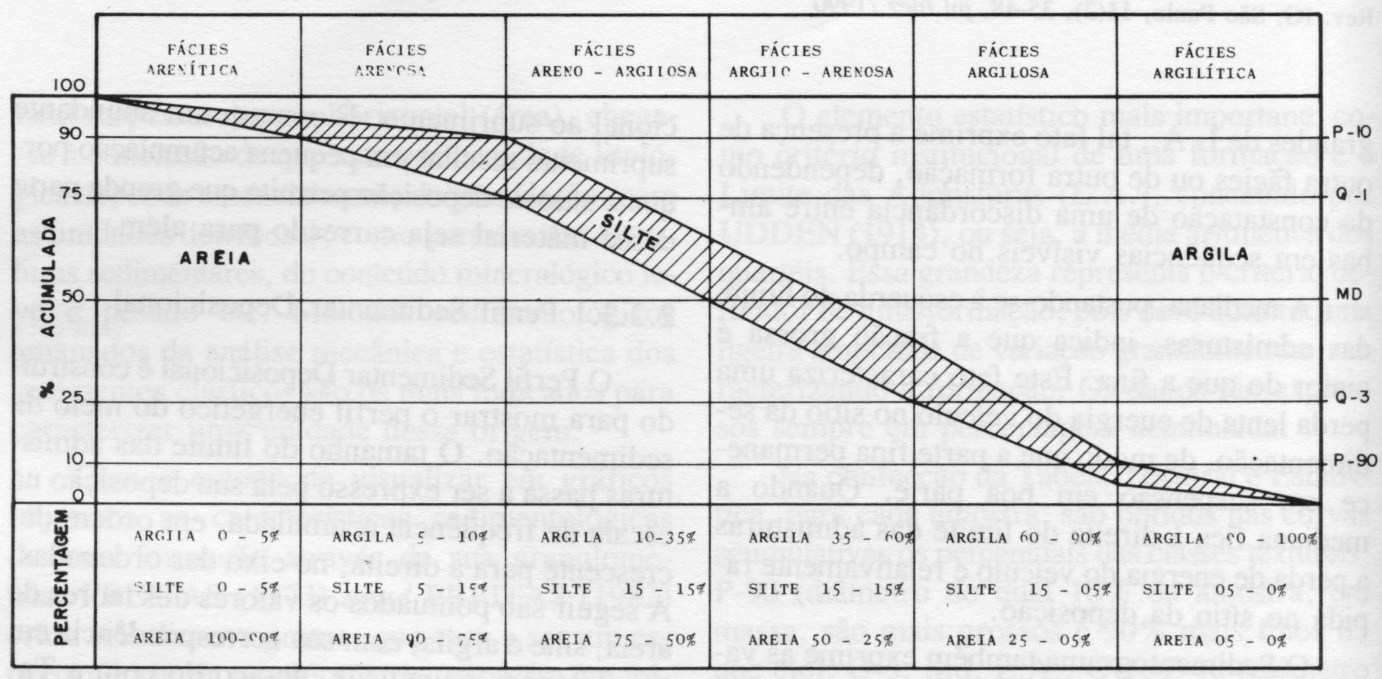

DIAGRAMA 1 - Classificação quantitativa das fácies das texturas areia e argila.

No Gráfico 2 apura-se que o desenho das texturas areia, silte e argila tem também significado energético. Quando o espectro do teor de silte segue em desenho uma direção mais ou menos horizontal, ora dentro da fração grossa, ora dentro da fração fina, isto significa a presença de duas fácies distintas na deposição, uma com maior energia (acima da mediana) e outra com menor (abaixo da mediana).

\subsubsection{Perfil Sedimentar Textural}

Este perfil (Gráfico 3) dá ênfase à distribuição quantitativa das texturas ao longo de uma série de amostras dispostas na abcissa. A base do gráfico repousa na variação quantitativa da textura areia, expressa em freqüência acumulada (Tabela Textural e Estatística), no sentido decrescente para a direita. Também são pontuados os valores de L.A. de acordo com a sua freqüência acumulada.

As fácies texturais admitidas são calibradas segundo os diagramas 1 e 2 . O Diagrama 1 refere-se às relações entre a argila $\mathrm{e} a$ areia quando a textura silte não ultrapassa $15 \%$. Ele representa as seguintes fácies de $A$ a $F$ :

\section{A - Fácies arenítica}

argila ........... $0-5 \%$

silte............. $0-5 \%$

areia $\ldots \ldots \ldots \ldots \ldots .100-90 \%$

B - Fácies arenosa

argila $\ldots \ldots \ldots \ldots \ldots 55-10 \%$

silte............ $5-15 \%$

areia $\ldots \ldots \ldots \ldots \ldots .90-75 \%$

C - Fácies areno-argilosa

argila $\ldots \ldots \ldots \ldots \ldots .10-35 \%$

silte............. $15-15 \%$

areia ............ $75-50 \%$
D - Fácies argilo-arenosa argila .............. $35-60 \%$

silte............ $15-15 \%$

areia $\ldots \ldots \ldots \ldots \ldots .50-25 \%$

E - Fácies argilosa

argila $\ldots \ldots \ldots \ldots \ldots .60-90 \%$

silte ............ $15-05 \%$

areia .............. $25-05 \%$

F - Fácies argilítica

argila $\ldots \ldots \ldots \ldots \ldots .90-100 \%$

silte............ $05-0 \%$

areia ............ $05-0 \%$

O Diagrama 2 trata das relações entre o silte de um lado e a areia e a argila de outro. Neste caso é necessário atentar para o fato de que o silte é um produto da areia sob forte intemperismo físico, pois mineralogicamente o silte contém $90 \%$ de quartzo. Assim sendo, no Diagrama 2 há duas seqüências distintas. A primeira exprime o comportamento areia-silte, onde o silte varia de 100 a $25 \%$; a segunda trata do comportamento silte-argila, onde o silte provém do quartzo e a argila do intemperismo químico dos feldspatos, biotita, piroxênios e anfibólios, para citar apenas as fontes principais. Neste caso, a areia varia de 10 a $0 \%$, o silte de 40 a $25 \%$ e a argila de 75 a $50 \%$. Neste segundo caso há duas origens para o material, o silte provindo do intemperismo físico e a argila, do intemperismo químico. Por tais razões há uma quebra do padrão do Diagrama 2 ao passar da fácies arenosiltosa para a argilo-siltosa.

Convém salientar que a areia e a argila são antagônicas (no segundo caso); quando há aumento de argila, diminui a areia, ficando o silte insensível. No caso do silte também há antagonismo com a argila, pois o aumento do silte fazse a expensas da argila, em relação à textura rica em silte (40 a $25 \%)$. 
O Diagrama 2 representa as seguintes fácies, de $G$ a $L$ :

G - Fácies síltica

argila $\ldots \ldots \ldots \ldots \ldots 0 . \ldots 00$

silte.............. $100-81 \%$

areia $\ldots \ldots \ldots \ldots \ldots, 0,15 \%$

H - Fácies siltosa

argila $\ldots \ldots \ldots \ldots \ldots 44-8 \%$

silte............ $81-62 \%$

areia $\ldots \ldots \ldots \ldots \ldots$. $15-30 \%$

I - Fácies silto-arenosa

argila $\ldots \ldots \ldots \ldots \ldots, 8-12 \%$ silte............. $62-43 \%$

areia ............ $30-45 \%$

J - Fácies areno-siltosa

argila $\ldots \ldots \ldots \ldots \ldots .12-15 \%$

silte............ $43-25 \%$

areia ............ $45-60 \%$

K - Fácies argilo-siltosa

argila ............ $50-63 \%$

silte............. $40-32 \%$

areia ............ $10-5 \%$

L - Fácies argilítico-siltosa

argila ............6 $63-75 \%$

silte............. $32-25 \%$

areia $\ldots \ldots \ldots \ldots \ldots .5-0 \%$

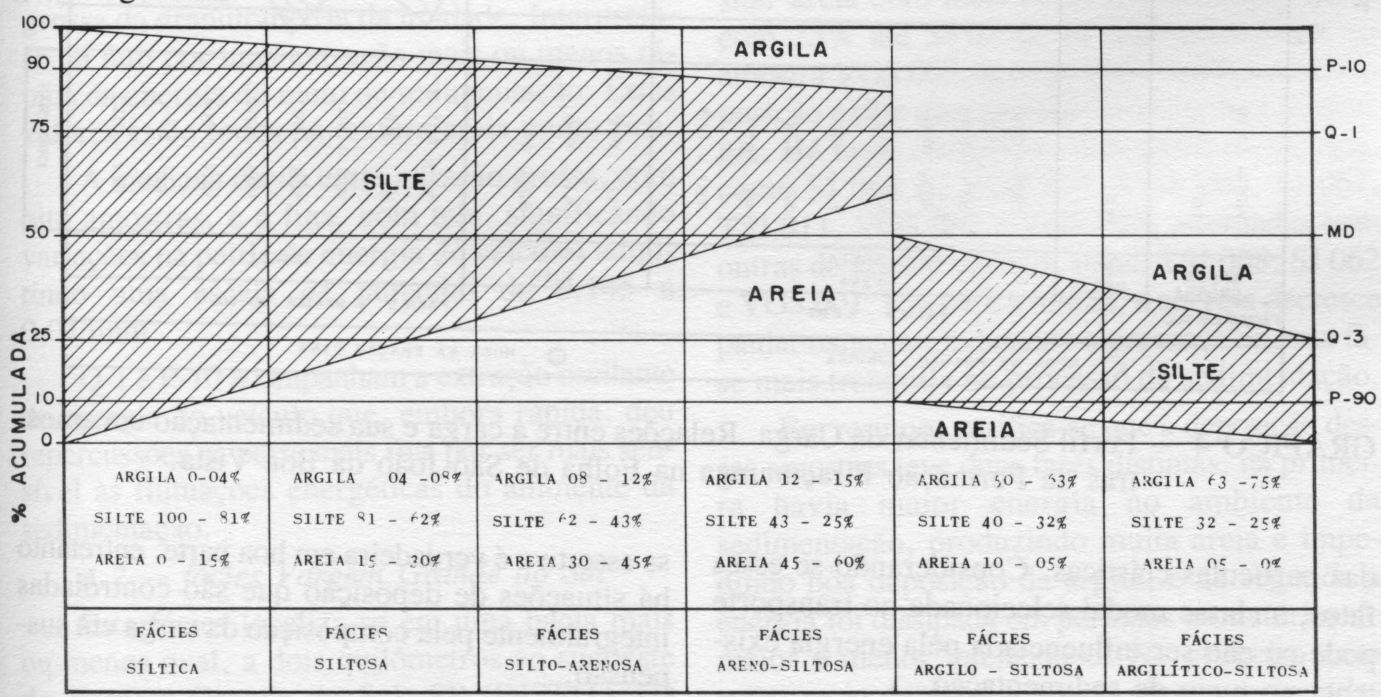

DIAGRAMA 2 - Classificação quantitativa das fácies da textura silte.

No processo intempérico a textura areia precede as demais e pode ser tida como fonte de silte e argila. Na fase areia os minerais constituintes são quartzo, feldspatos, micas, estaurolita, cianita, monazita, zircão, hornblenda, augita, pigeonita, ilmenita, magnetita e calcita, para citar os mais comuns. Nesta fase textural o intemperismo físico predomina. Da textura areia derivam, de um lado, a textura silte e, de outro, a argila. Essa bifurcação é resultante do tipo de intemperismo que amadurece a areia, pois no silte mineralogicamente os constituintes são quartzo na maioria dos grãos e, secundariamente, minerais de argila micáceos e clorita, o que indica um amadurecimento textural em condições severas de intemperismo químico, aliado ainda ao físico, como nos loessitos. Já na textura argila os minerais comuns são os da argila, hidroalumino-silicatos com estrutura de filossilicatos, como caolinita, montmorilonita, ilita, clorita e glauconita. Em condições tropicais os minerais de argila são gibsita, diásporo ou boehmita.

\subsubsection{Perfil Sedimentar da Carga}

Neste perfil (Gráfico 4), as classes modais detectadas são dispostas em ordem decrescente da esquerda para a direita. Nesses compartimentos são colocadas as classes modais pertinentes, segundo os seus valores em percentagem acumulada, em série descendente. Também para a direita são representados os valores do limite das admisturas em percentagem acumulada, de acordo com as amostras apontadas na abcissa.

O gráfico em questão procura resolver quais são as relações entre a carga em suspensão no veículo aquoso e a sua sedimentação, no sentido de se avaliar se a deposição corresponde exatamente à composição da carga.

No transporte da carga, a sua seletividade é o resultado do movimento horizontal do veículo aquoso e da distância percorrida, quando também influi a viscosidade da água e a sua densidade. No local da deposição a sedimentação depende da carga e da velocidade de queda vertical 


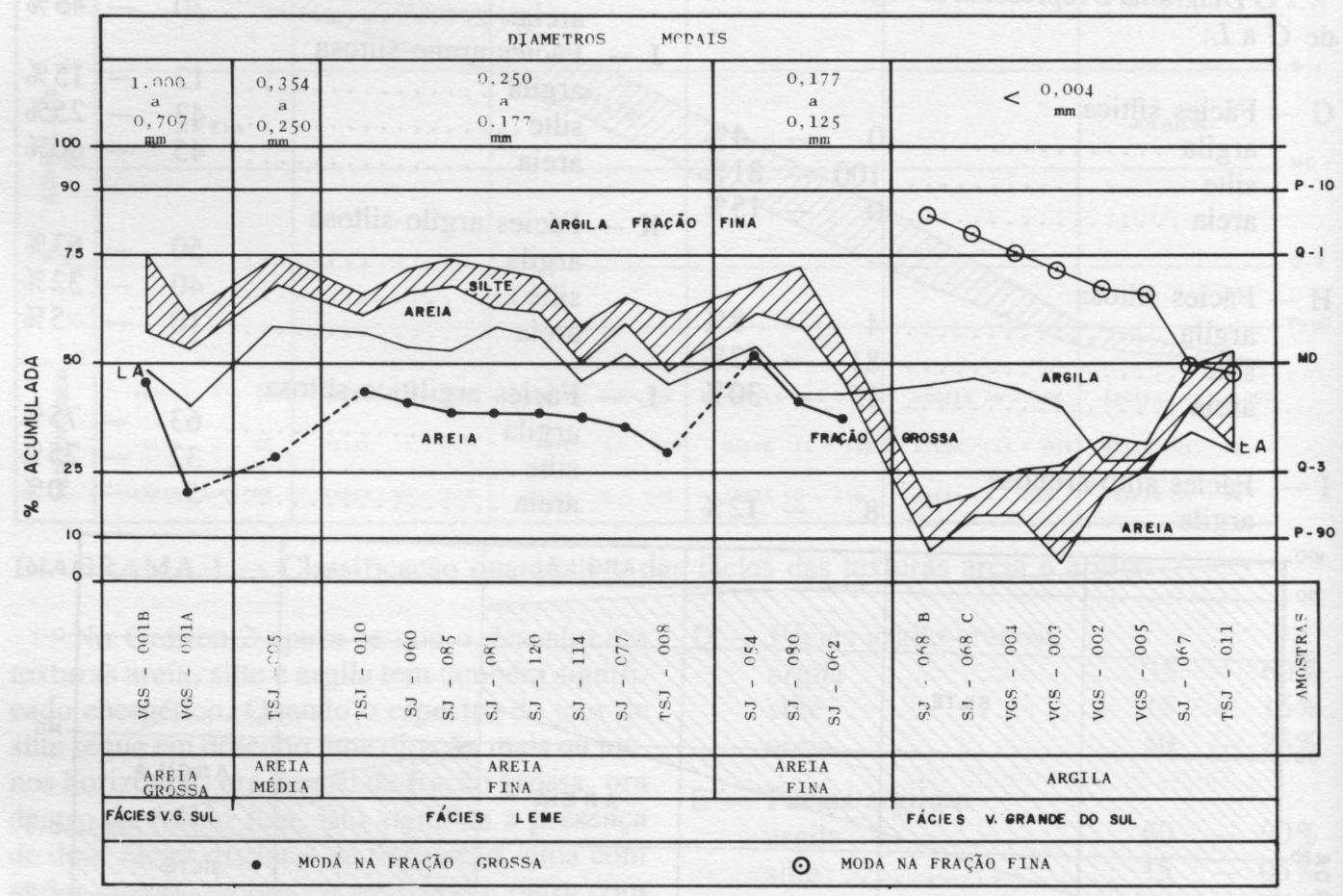

GRÁFICO 4 - Perfil Sedimentar da Carga. Relações entre a carga e sua sedimentação em amostras da Formação Piraçununga na Folha de São João da Boa Vista.

das partículas clásticas. Considerando-se esses fatos, a classe modal selecionada no transporte pode ou não ser influenciada pela energia existente no meio de sedimentação.

STOKES (1851) e RUBEY (1933) calcularam as velocidades de queda para partículas de determinados diâmetros, enquanto que HJULSTRÖM (1939) calculou as correspondentes velocidades limites ou críticas para que elas se mantenham em suspensão. Os valores da velocidade de queda na água admitem densidade de $2,7 \mathrm{~g} / \mathrm{cm}^{3}$, temperatura de $20^{\circ} \mathrm{C}$ e viscosidade de $0,01 \mathrm{~g} / \mathrm{cm} \times \mathrm{s}$.

Analisando-se esses dados verifica-se que a velocidade-limite ou crítica da suspensão das partículas é inferior à velocidade de queda ou assentamento, até a subclasse entre 0,125 e 0,088 $\mathrm{mm}$. A deposição de una dada partícula acima de $0,014 \mathrm{~cm} / \mathrm{s}$ tem uma trajetória parabólica na sua queda, devido às componentes vertical e horizontal.

A interpretação deste gráfico repousa no posicionamento da moda em relação à mediana $\mathrm{e}$ às frações grossa e fina, definidas pelo limite das admisturas. UDDEN (1914) acreditava que a composição granulométrica de um sedimento era controlada pelas condições que prevaleciam no ambiente de sedimentação. No nosso estudo es- sa assertiva é verdadeira em boa parte, entretanto há situações de deposição que são controladas integralmente pela composição da carga em suspensão.

\subsection{Interpretação}

\subsubsection{Sedimentograma}

Observando-se o espectro do Sedimentograma (Gráfico 1), apura-se que existem três registros distintos:

1 . - As amostras VGS 001 A e VGS 001 B indicam que o valor de L.A. discrepa para a esquerda, mostrando brusca variação granulométrica para o lado mais grosso.

20 - Constitui uma seqüência uniforme, pois L.A. vai de $0,091 \mathrm{~mm}$ (SJ 062) até $0,145 \mathrm{~mm}$ (SJ 067).

30 - Esta seqüência apresenta L.A. discrepando para a direita, caracterizando uma série de compoição mais fina, indo de $0,063 \mathrm{~mm}$ (TSJ 011) a $0,0025 \mathrm{~mm}$ (SJ $068 \mathrm{~B}$ ).

O segundo registro acima representa a imagem granulométrica da Formação Piraçununga, absolutamente distinta dos registros primeiro e terceiro. Como não há discordância geológica entre essas seqüências, segue-se que há três feições distintas pertencentes à Formação Piraçu- 
nunga, com uma delas mais extensa, como prova o seu maior número de amostras.

Do ponto de vista geológico há duas fácies, a primeira constituída pelo segundo registro, sendo denominada informalmente de fácies Leme, e a segunda reunindo os primeiro e terceiro registros, sendo chamada informalmente de fácies Vargem Grande do Sul, pois ambos formam um conjunto visível e único em escavações no campo.

\section{A - Expansão granulométrica e textura}

\section{A.1 - fácies Leme}

P-90, Q-3 e L.A. são quase paralelos, o que indica uma razoável uniformidade da fração grossa da granulometria da unidade. Interpretase tal fato por uma extração mais ou menos rápida da energia do meio de sedimentação. Estes valores estão todos na textura areia muito fina.

A mediana oscila entre a fração grossa, com oito amostras, e a fina, com três, significando variações na perda de energia do veículo, admitindo uma escala de tamanho de 0,145 a $0,013 \mathrm{~mm}$.

Q-1 e P-10 acompanham a extração oscilante de energia do veículo que, embora rápida, deu repercussões na parte mais fina por ser mais sensível às flutuações energéticas do ambiente da sedimentação.

\section{A. 2 - fácies Vargem Grande do Sul}

Esta fácies localiza-se em uma bacia mais ou menos oval, a dois quilômetros ao sudoeste de Vargem Grande do Sul, SP (INSTITUTO GEOLÓGICO, 1982). Nesta bacia há termos de granulação grossa no topo e fina na base, sem desconformidade, sendo referidas como amostras VGS. As amostras VGS 001 A e VGS 001 B são bem grossas, possuindo, além da textura areia, a de grânulos (VGS 001 B, Tabela Textural e Estatística).

As amostras VGS 002, 003, 004 e 005 pertencem a fácies granulométricas bem mais finas, onde também estão TSJ 011 , SJ 068 B e SJ 068 $\mathrm{C}$, referentes todas a uma expansão para o lado fino, com recuos para o lado grosso (TSJ 011 e VGS 005). Isto demonstra que houve entrada de energia na bacia, seguida de pulsações que extraíram a energia do meio de sedimentação, causando maior riqueza de termos finos.

P-90, Q-3 e L.A. mostram essas variações extremas de fases tranqüilas com outras energizadas. A disposição do espectro do sedimentograma leva à admissão da possibilidade de influências tectônicas sincrônicas com a deposição nesta bacia (existe uma falha de direção aproximada N-S, no local).

A mediana repousa na fração fina, o que indica que os termos finos foram favorecidos no ritmo da deposição. A disposição quase paralela de Q-1 e P-10 reafirma o favorecimento da deposição da parte fina da litologia.

Na fácies Vargem Grande do Sul a mediana fica na argila em seis amostras, no silte em duas e na areia em uma; na fácies Leme a mediana situa-se na areia em dez amostras e no silte em três.

\subsubsection{Perfil Sedimentar Deposicional}

No Gráfico 2, de SJ 081 até SJ 114, o ambiente dispunha de energia suficiente para depositar areia com mais de $50 \%$ até $68 \%$ e argila com $25 \%$ até $35 \%$; de SJ 068 até o final, na amostra VGS 005, nota-se que o ambiente da deposição exibe uma grande variação na sua energia. Há fases tranqüilas, com pequena energia, como SJ 068 B, VGS 004, VGS 003, SJ 067, TSJ 011, VGS 002 e VGS 005, alternadas com outras de grande energia, como TSJ 008, SJ 062 e VGS 001. Daí para a direita, a energia decresce paulatinamente, indicando a presença de uma fase mais tranqüila no processo da sedimentação.

Em resumo, verifica-se que a deposição dessas amostras teve duas fases distintas, na primeira havia maior energia no ambiente da sedimentação, produzindo muita areia e impedindo boa deposição da argila, e na segunda a energia foi dissipada em períodos oscilatórios de maior e menor intensidade. No primeiro caso tratar-se-ia de deposição em planos de inundação e, no segundo, em lagoas ou bacias sujeitas ao controle das cheias e vazantes fluviais.

\subsubsection{Perfil Sedimentar Textural}

A apreciação do Gráfico 3 é feita às custas do teor da areia decrescendo em valores de freqüência acumulada da esquerda para a direita. Esta disposição mostra a queda percentual da areia para o lado direito, que é o lado mais fino da distribuição granulométrica acumulada. Esta progressiva diminuição da textura areia mostra que a energia do veículo foi gradativamente sendo eliminada e, conseqüentemente, várias fácies são admitidas em virtude da computação dos diagramas 1 e 2: areno-argilosa, argilo-arenosa, argilosa e argilítica. Observa-se que: $19-\mathrm{O}$ conjunto de amostras não se enquadra nas fácies do Diagrama $2 ; 2$ ? - as amostras correspondentes às fácies Vargem Grande do Sul caem à direita do gráfico, com exceção de VGS 001 A e VGS $001 \mathrm{~B}$, compondo as fácies mais finas (argilo-arenosa, argilosa e argilítica), enquanto que estas duas últimas amostras (VGS $001 \mathrm{~A} \mathrm{e}$ VGS 001 B) caem na fácies à esquerda (areno- 
argilosa), que é aquela em que ficam as amostras da fácies Leme, isto porque, como já vimos, essas duas amostras representam grandes entradas de energia na bacia restrita do sudoeste de Vargem Grande do Sul.

\subsubsection{Perfil Sedimentar da Carga}

Os nossos resultados (Gráfico 4) indicam que geralmente, quando a mediana acha-se na fração grossa, as classes modais posicionam-se nela; quando a mediana acha-se na fração fina, as classes modais também a acompanham. Esta averiguação indica que as condições que prevaleceram no ambiente de sedimentação são responsáveis pela granulometria do sedimento clástico. Este fato ocorre na maioria das amostras em que a moda ocupa as classes $0,354-$ $0,250 \mathrm{~mm}$ e $0,250-0,177 \mathrm{~mm}$, que se acham solidárias com a posição da mediana na fração grossa. Na fração fina as modas acompanham o posicionamento da mediana somente na classe menor do que $0,004 \mathrm{~mm}$.

Existem contudo situações em que a carga influiu diretamente na deposição; são as amostras em que a moda está na fração fina e a mediana na grossa, ou o inverso, a moda está na fração grossa e a mediana na fina. As amostras VGS 001 A, VGS 001 B, SJ 114, TSJ 008, SJ 080 e SJ 062 têm as classes modais na fração grossa e a mediana na fina, constituindo seis amostras excepcionais, contra dezesseis normais.

Examinando-se globalmente o Gráfico 4 verifica-se que não há classes modais entre 0,707 e 0,354 mm e nem no silte; nota-se também que as modas das amostras de diâmetros modais de 1,000 e $0,125 \mathrm{~mm}$ permanecem na fração grossa, abaixo de $0,004 \mathrm{~mm}$ permanecem na fração fina. No primeiro caso $(1,000$ a $0,125 \mathrm{~mm})$ a curtose é menor do que 1 , indicando que as modas se aproximam mais de Q-3, proporcionando uma assimetria à esquerda (lado mais grosso). No segundo (menor do que $0,004 \mathrm{~mm}$ ) a curtose é maior do que 1 , o que mostra a proximidade das modas com Q-1 (lado mais fino), derivando uma assimetria à direita. Conclui-se que há dois perfis de carga distintos, um com modas de 1,000 a $0,125 \mathrm{~mm}$ em maioria e outro abaixo de $0,004 \mathrm{~mm}$. Ao primeiro (com exceção das amostras VGS 001 A e VGS 001 B), anotamos a fácies Leme, a mais extensa e que caracteriza esta formação; ao segundo perfil atribuímos a fácies Vargem Grande do Sul, inteiramente distinta da primeira e ocupando uma bacia limitada. As amostras VGS 001 A e VGS 001 B, embora com perfil modal semelhante à fácies Leme, representam uma entrada de maior energia na fácies Vargem Grande do Sul.
$\mathrm{Na}$ fração abaixo de $0,004 \mathrm{~mm}$ as modas decrescem de $84 \%$ para $48 \%$ (percentagem acumulada), indicando que houve uma gradual migração das modas para a posição da mediana, fato que caracteriza uma lenta progressão da energia para as bordas da bacia, onde estão as amostras TSJ 011 e SJ 067; as demais referemse ao centro da bacia.

Já as amostras da fácies Leme têm as modas com pequena variação na sua posição no Gráfico 4. Tal fato indica um ambiente com boa energia, sobretudo constante, mantendo assim condições uniformes de sedimentação. Alguma variação ambiental é encontrada nas modas posicionadas nas classes $0,354-0,250 \mathrm{~mm}$ e 0,177 $-0,125 \mathrm{~mm}$. A primeira classe indica depósitos em águas correntes e a última em águas calmas. As amostras das classes $0,250-0,177 \mathrm{~mm}$ referem-se a planos de inundação, onde fisicamente o ambiente é muito uniforme.

\subsection{Resumo Analítico dos Perfis Sedimentares}

O Gráfico 2 permite uma análise do meio de deposição, mostrando:

10 - Proporções extremamente variáveis de areia e argila, em contraposição a proporções razoavelmente uniformes de silte, o que o Diagrama 1 expõe. A areia varia de cerca de 4 a $69 \%$ do total; a argila de cerca de 24 a $82 \%$ do total; o silte varia de cerca de 5 a $24 \%$ do total.

2 : - Uniformidade nas proporções areiaargila na parte esquerda do gráfico, em contraposição a grandes variações na parte direita (mais da metade do gráfico).

30. - Presença invariável de areia na fração fina na parte esquerda do gráfico, em contraposição a extrema variação na parte direita (mais da metade do gráfico), onde algumas amostras mostram argila na parte grossa.

$4^{\circ}$ - Mediana na fração grossa na parte esquerda do gráfico e mediana na fração fina à direita (pouco mais da metade do gráfico).

50 - Presença das amostras do sítio a sudoeste de Vargem Grande do Sul na parte direita do gráfico; nessa parte apenas as amostras SJ 062, SJ 114 e TSJ 008 não pertencem a esse sítio, fazendo parte de dois picos de invasão da areia na fração fina.

Esses fatos permitem as seguintes conclusões:

1. a - A pobreza de silte caracteriza o seu não transporte em maiores quantidades, ou seja, pequeno fornecimento pela área-fonte (VIEIRA, 1982a).

2a - A extrema variação da proporção areia-argila na parte direita do gráfico mostra os- 
cilações de energia no sítio de deposição ao sudoeste de Vargem Grande do Sul, com períodos de extrema tranqüilidade, permitindo deposição de alta taxa de argila, contrapondo-se a períodos menos tranqüilos, permitindo aumento da areia, enquanto que fora dessa porção teria havido uniformidade de um meio mais enérgico.

$3^{\text {a }}$ - O meio de deposição fora do sudoeste de Vargem Grande do Sul era tão enérgico quanto o meio de transporte, enquanto que o meio de deposição nesse sítio era menos enérgico que o de transporte.

O Gráfico 3 permite uma análise comparativa entre o transporte e a deposição, mostrando:

1. - Razoável uniformidade no teor de silte, ou seja, o decréscimo da classe areia é compensado pelo aumento da classe argila.

2 . - Presença de areia na fração fina nos dois terços esquerdos do gráfico e presença de argila na fração grossa na parte direita.

3? - Presença de amostras do sudoeste de Vargem Grande do Sul no terço direito do gráfico, com exceção das amostras VGS 001 A e VGS $001 \mathrm{~B}$.

Esses fatos permitem as seguintes conclusões:

1. a A porção ao sudoeste de Vargem Grande do Sul compõe uma fácies argiloarenosa, uma fácies argilosa e uma argilítica predominantemente, enquanto que as outras porções compõem uma fácies areno-argilosa e uma argilo-arenosa, mostrando que o meio de deposição destas foi mais enérgico que o daquela porção.

2. a - A porção ao sudoeste de Vargem Grande do Sul caracteriza um ambiente deposicional tranqüilo, com energia inferior ao agente transportador, sugerindo que correntes de água ou enxurradas teriam aí formado uma planície de inundação, que poderia ter dado origem a um lago, pelo menos temporariamente.

3? - As amostras VGS 001 A e VGS 001 $B$ caracterizam um instante de aumento de energia no meio deposicional, que pode ser explicado por uma fase de enchente rápida na planície de inundação ou por um aporte de material mais grosso num lago, ocasionado por estação chuvosa, sendo cabível uma influência tectônica.

As conclusões dos gráficos levam à interpretação da existência de uma planície de inundação ou lago ao sudoeste da cidade de Vargem Grande do Sul, inserida num contexto sedimentar maior, essencialmente aquoso, todavia mais enérgico, constituindo enxurradas descendo ao longo de vertentes, formando correntes nas baixadas. Os sedimentos finos dessa porção não fo- ram encontrados em outras regiões da Formação Piraçununga, o que sugere um ambiente de sedimentação predominantemente tranqüilo, por vezes perturbado por aumento de competência, enquanto que o restante daquela unidade estratigráfica mostra compor um ambiente permanentemente mais enérgico.

O Gráfico 4 permite uma comparação entre a carga transportada e sua deposição, mostrando:

10 - Razoável estabilidade nas proporções entre areia, silte e argila até o diâmetro de $0,125 \mathrm{~mm}$ e instabilidade nos diâmetros da argila.

20. - Ausência de classes modais nos diâmetros texturais das subclasses $0,707-0,354$ e $0,125-0,004 \mathrm{~mm}$.

3? - Moda na classe areia nos diâmetros mais grossos (até $0,125 \mathrm{~mm}$ ); moda mutto próxima ao limite silte-argila ou na classe argila para os diâmetros correspondentes à argila (aspecto construcional do gráfico).

4? - Moda na fração grossa nos diâmetros maiores, até $0,125 \mathrm{~mm}$ e moda na fração fina nos diâmetros menores que $0,004 \mathrm{~mm}$.

50 - Invasão da classe areia na fração fina nos diâmetros modais maiores, até $0,125 \mathrm{~mm}$ e em parte nos diâmetros modais menores que $0,004 \mathrm{~mm}$; invasão da classe argila na fração grossa em parte dos diâmetros modais menores que $0,004 \mathrm{~mm}$.

$6^{0}$ - Localização das amostras coletadas ao sudoeste da cidade de Vargem Grande do Sul à direita do gráfico (diâmetro modal menor que $0,004 \mathrm{~mm}$ ) e presença das amostras coletadas fora desse sítio, à esquerda do gráfico (diâmetro modal maior que $0,125 \mathrm{~mm}$ ), com exceção das amostras VGS 001 A e VGS 001 B.

$7^{\circ}$ - Caráter mais fino das amostras situadas ao sudoeste de Vargem Grande do Sul do que as situadas em outros locais (idem exceção anterior).

Esses fatos permitem as seguintes conclusões:

1. - Competência pouco variável do meio de deposição do material situado fora do sítio a sudoeste da cidade de Vargem Grande do Sul e competência muito variável do meio de deposição nesse sítio.

2a - Grande sensibilidade do material do sítio de deposição a sudoeste de Vargem Grande do Sul a pequenas variações de competência, em contraposição à pequena sensibilidade do material de outros pontos a pequenas variações (em virtude do caráter mais fino daquele).

3 a - Meio habitualmente pouco enérgico no sítio de deposição a sudoeste de Vargem 
Grande do Sul, com algum aumento esporádico de energia, causando acréscimo da classe areia e meio invariavelmente mais enérgico fora desse sítio.

4 a - Ótimo do transporte ou da deposição sempre fora do intervalo das subclasses texturais entre 0,125 e $0,004 \mathrm{~mm}$ (não há classe modal nele), caracterizando um ótimo na classe areia fora do sudoeste de Vargem Grande do Sul, em contraposição a outro ótimo na classe argila nesse local.

5 a - Enriquecimento da classe areia em partes do sítio a sudoeste de Vargem Grande do Sul, causado por fatores locais (agitação temporária da água) e não por aumento da energia do meio de transporte, o que fica caracterizado pela moda na classe argila nas amostras com areia na fração fina. Fora desse sítio a riqueza da classe areia é motivada por um transporte cujo ótimo esteve sempre nessa classe, caracterizando um transporte e um meio de deposição permanentemente mais enérgicos.

\section{CONTEÚDO PALEONTOLÓGICO}

A primeira descrição da megaflora de Vargem Grande do Sul deve-se a MEZZALIRA (1961/62) que assinalou a presença de uma Myrtales-Melastomataceae - Tibouchina izildaisabelae Mezzalira, 1961/62, e de espécies referidas preliminarmente a Ranales - Anonaceae, Ebenales e Rutales.

DUARTE \& REZENDE-MARTINS, em estudos posteriores (1983 e 1985), classificaram mais as seguintes espécies de angiospermas dicotiledôneas, distribuídas pelas suas diversas famílias:

Cassia parkerii Duarte \& Rezende-Martins, 1983

C. elliptica Duarte \& Rezende-Martins, 1983

C. parabicapsularis Duarte \& Rezende-Martins, 1983

Machaerium nervosum Duarte \& RezendeMartins, 1983

Platypodium potosianum Engelhardt, 1897

Camptosema primum Duarte \& RezendeMartins, 1983

Cedrela arcuata Duarte \& Rezende-Martins, 1983

Serjania mezzalirai Duarte \& Rezende-Martins, 1983

Sapindus ferreirai Duarte, 1972

Maytenus fragilis Duarte \& Rezende-Martins, 1985

Eugenia vargensis Duarte \& Rezende-Martins, 1985

E. punctata Duarte \& Rezende-Martins, 1985

Psidium adornatum Duarte \& Rezende-Martins, 1985
Myrcia diafana Duarte \& Rezende-Martins, 1985 Calyptranthes argilosa Duarte \& RezendeMartins, 1985

Gomidezia costata Duarte \& Rezende-Martins, 1985

Symplocos dealbata Duarte \& Rezende-Martins, 1985.

Destacaram nessa megaflora o aparecimento, pela primeira vez, dos gêneros Camptosema e Gomidezia, no estado fóssil.

Entre os espécimes encontrados e listados aparece Sapindus ferreirai Duarte, 1972, descrito pela primeira vez por DUARTE (1972) em sedimentos da Formação Pirabas, do nortenordeste brasileiro, considerada, na ocasião, como de idade miocênica e atualmente como oligomiocênica (FERREIRA \& FERNANDES, 1986). Essa mesma espécie é ainda descrita na bacia de Gandarela, Minas Gerais (DUARTE \& MELO FILHA, 1980), de idade terciária.

A proposição de idade holocênica, sem justificativa satisfatória, para essa megaflora ocorrente em Vargem Grande do Sul, por DUARTE \& REZENDE-MARTINS (1985), é suscetível de discussão, pois não se pode imaginar que a espécie Sapindus ferreirai Duarte tenha uma duração tão grande (do Mioceno ou Oligoceno ao Holoceno, mais ou menos vinte e cinco milhões de anos), uma vez que o período de vida das espécies é geologicamente limitado (SCHIMPER, 1869), embora a dispersão genérica possa ser elevada.

Quanto ao gênero Sapindus, que aparece pela primeira vez no Cretáceo superior, vindo até o Recente, com um número variável de espécies distribuídas ao longo dos períodos do Cenozóico, alcança sua plenitude específica no Eoceno da América do Norte (vinte espécies), decrescendo do Oligoceno em diante (DUARTE, 1972). As próprias variações climáticas influenciaram no desaparecimento de umas espécies e no aparecimento de outras melhor adaptadas ao paleoambiente da época.

A presença de asa de inseto HomopteraCercopidae, com características bastante divergentes das dos atuais, sugere, com cautela (MARTINS-NETO, 1989), uma idade terciária a partir do Mioceno para os sedimentos psamopelíticos de Vargem Grande do Sul.

\section{IDADE DA FORMAÇÃO PIRAÇUNUNGA}

Por sua natureza predominantemente afossilífera, a datação da Formação Piraçununga tem sido feita em base essencialmente especulativa, com fulcro em eventos climáticos e tectônicos. FREITAS et al. (1979) atribuíram-na ao Oligoceno; SOARES \& LANDIM (1973 e 1976) apud VIEIRA (1982a) ao Quaternário; VIEIRA (1982a) e 
AZEVEDO \& MASSOLI (1984) como provavelmente ao Terciário; MASSOLI (1980, 1981 e 1983) e TOMINAGA (1981) ao Terciário e VIEIRA (1982b) ao Plio-Pleistoceno.

A primeira assinalação da ocorrência de vegetais fósseis nos sedimentos psamopelíticos de Vargem Grande do Sul foi feita por MEZZALIRA (1961/62), que sugeriu na ocasião idade pleistocênica. Estudos recentes de DUARTE \& REZENDE-MARTINS (1983 e 1985), sobre a megaflora ali encontrada, propuseram idade holocênica, suscetível de discussão e revisão nesta oportunidade.

A presença da megaflora e de inseto na fácies Vargem Grande do Sul permite sugerir idade oligomiocênica, a qual pode ser estendida, com cautela, à fácies Leme (portanto a toda a Formação Piraçununga) ou, pelo menos, ao início da sedimentação desta unidade, por tratarse a fácies Vargem Grande do Sul de uma deposição tranqüila de pequena parte da Formação Piraçununga, sincrônica com o restante ou, no mínimo, com a parte basal.

\section{CONSIDERAÇÕES FINAIS}

O estudo granulométrico precedente permite propor para a porção psamopelítica do sudoeste da cidade de Vargem Grande do Sul, a designação informal de fácies Vargem Grande do Sul, pertencente à Formação Piraçununga e distinta do restante da mesma (fácies Leme) por possuir uma camada de cerca de três metros de espessura de argila contendo moldes de folhas vegetais citadas neste trabalho, caracterizando portanto um ambiente tranqüilo de deposição, com águaș pouco ou não agitadas (planície de inundação ou lago), ao contrário do ambiente comum de constituição dessa formação, que se caracteriza por situação provável de movimentos de massa, ou talvez de rede hidrográfica.

Os mapeamentos regionais prévios desprezaram os materiais cenozóicos, especialmente pela pequena espessura (no local, cerca de nove metros); assim o primeiro mapa que destaca os sedimentos terciários e quaternários no local é o do INSTITUTO GEOLỎGICO (1982), elaborado na escala 1:50.000, o qual distingue essa porção sudoeste da cidade de Vargem Grande do Sul do restante da deposição terciária, em função da granulação mais fina. Um ano antes, COTTAS et al. (1981) e TOMINAGA (1981) já apresentavam a parte a sudoeste de Vargem Grande do Sul como pertencente ao Cenozóico.

MEZZALIRA (1961/62) sugeria “deposição em lagos de águas muito calmas, quasi paradas e limpas, não tendo os fósseis indícios, pelo menos aparentemente, de terem sofrido algum transpor- te”. TOMINAGA (1981) já destacava essa fácies ao afirmar: "Os sedimentos Terciários a Oeste e Noroeste de Vargem Grande do Sul, apresentam fração arenosa dominante, tornando-os muito porosos e permeáveis. Ao Sul da mesma cidade, verifica-se a predominância da fração argilosa nesses sedimentos. Na Faz. Cachoeirinha, a $4 \mathrm{~km}$ a Sul de Vargem Grande do Sul, ocorre uma camada de argila branca com 3 metros de espessura, contendo moldes de folhas vegetais, os quais estão em estudo".

Todavia, técnicos da UNIVERSIDADE ESTADUAL PAULISTA "JÚLIO DE MESQUITA FILHO” (1984), elaborando também o mapa geológico da Folha de São João da Boa Vista (embora com outra finalidade), na mesma escala que a adotada pelo INSTITUTO GEOLÓGICO (1982), chamam esta porção de Formação Aquidauana (Permiano-Carbonífero), mesmo tendo MEZZALIRA (1961/62) já citado a existência de folhas de angiospermas no local e TOMINAGA (1981), assim como o INSTITUTO GEOLÓGICO (1982), terem mostrado tratar-se de sedimento terciário pouco espesso. Portanto a afirmação de fls. 62 daquele relatório - "Um outro tipo de depósito de argila foi observado em uma lavra abandonada na fazenda Cachoeira. Trata-se provavelmente de alteração in situ de veios pegmatíticos, levando à formação de argilas de coloração branco-roxeada..." - contradiz-se com o seu mapeamento e com as idéias dos autores anteriores.

Com base no conteúdo paleontológico da fácies Vargem Grande do Sul, é sugerida uma idade oligomiocênica para esses sedimentos, com possibilidade de extensão para a fácies Leme, ou para a sua porção basal, pois não se verifica no campo nenhuma discordância entre ambas, havendo, ao contrário, uma gradual passagem entre as mesmas.

\section{REFERÊNCIAS BIBLIOGRÁFICAS}

AZEVEDO, A.A.B. \& MASSOLI, M. - 1984 - Geologia da Folha de Aguaí, SP. Revista do Instituto Geológico, São Paulo, 5(1/2):39-46.

COTTAS, L.R.; FIORI, A.P.; LANDIM, P.M.B. - 1981 - Divisão faciológica do Subgrupo Itararé e da Formação Aquidauana no nordeste do Estado de São Paulo. IN: SIMPÓSIO REGIONAL DE GEOLOGIA, $3^{\circ}$., Curitiba, PR. Atas. São Paulo, Sociedade Brasileira de Geologia. v.2, p.103-115.

DUARTE, L. - 1972 - A flórula da Formação Pirabas, Estado do Pará, Brasil. São Paulo, Instituto de Geociências, USP. 156p. (Tese de Doutoramento) Inédita.

\& MELO FILHA, M.C. - 1980 - Flórula cenozóica de Gandarela, MG I Anais 
da Academia Brasileira de Ciências, Rio de Janeiro, 52(1):77-91. 4 ests. .

\& REZENDE MARTINS, A.F.P. 1983 - Contribuição ao conhecimento da flora cenozóica do Brasil: Jazigo Vargem Grande do Sul, SP. Série Taubaté I. Anais da Academia Brasileira de Ciências, Rio de Janeiro, 55(1):109-121.

\& - 1985 - Contribuição ao conhecimento da flora cenozóica do Brasil: Jazigo Vargem Grande do Sul, SP. Série Taubaté II. Brasília, DNPM/DGM. (Série Geologia, 27 - Seção de Estratigrafia e Paleontologia, 2). Págs. 565-576.

FERREIRA, C.S. \& FERNANDES, A.C.S. 1986 - Uma nova ocorrência de coral hermatípico na Formação Pirabas, ÓligoMioceno do Estado. Anais da Academia Brasileira de Ciências, Rio de Janeiro, 58(4):609-610.

FREITAS, R.O. - 1982 - Definição estratigráfica do Grupo Bauru por sedimentogramas. São Paulo, Instituto Geológico. 86p. (Boletim, 6).

; MEZZALIRA, S.; ODA, G.H.; VIEIRA, P.C.; TORRES, C.C.; HACHIRO, J.: TOMINAGA, L.K.; DEHIRA, L.K.: MASSOLI, M.; AZEVEDO, A.A.B.; PRESSINOTTI, M.M.N. - 1979 - Projeto de levantamento geológico de formações superficiais. IN: SIMPÓSIO REGIONAL DE GEOLOGIA, 2\%, Rio Claro, SP. Atas. Rio Claro, SP., Sociedade Brasileira de Geologia, Núcleo de São Paulo. v.2, p.263-277.

HJULSTRÖM, F. - 1939-Transportation of detritus by running water: recent marine sediments. Bulletin of American Association Petroleum Geologists, Tulsa, Okla., 39(1):5-31.

INSTITUTO GEOLÓGICO - 1982 - Formações geológicas de superfície: Folha geológica de São João da Boa Vista. Coord.: Prof. Dr. Ruy Osório de Freitas. São Paulo. Escala 1:50.000 (SF-23-V-C-VI-3).

MARTINS-NETO, R.G. - 1989 - Novos insetos terciários do Estado de São Paulo. Revista Brasileira de Geociências, São Paulo, 19(3):375-386.
MASSOLI, M. - 1980 - Geologia da Folha de Santa Rita do Passa Quatro. Revista do Instituto Geológico, São Paulo, 1(1):7-14.

- 1981 - Geologia do Município de Santa Rita do Passa Quatro. Revista do Instituto Geológico, São Paulo, 2(2):35-45.

- 1983 - Geologia da Folha de Piraçununga, SP. Revista do Instituto Geológico, São Paulo, 4(1/2):25-51.

MEZZALIRA, S. - 1961/62 - Novas ocorrências de vegetais fósseis cenozóicos no Estado de São Paulo. Revista O IGG, São Paulo, 15(único):73-94.

RUBEY, W.W. - 1933 - Settling velocities of gravel, sand and silt particles. American Journal of Science, New Haven, Conn., 25(3):325-388.

SCHIMPER, W. - 1869 - Traité de Paleontologie vegetale ou la flore du monde primitif dans ses rapports avec les formations geologiques et la flore du monde actuel. Paris, J.B. Baillière et Fils, Librairies de la Académie Impériale de Médicine. t.1. 738p.

STOKES, E.G. - $1851-$ On the efect of the internal friction of fluids on the motion of pudulums. Transf. Camb. Philos. Society, 9(2):8-106.

TOMINAGA, L.K. - 1981 - Geologia da Folha de São João da Boa Vista. Revista do Instituto Geológico, São Paulo, 2(1):21-28.

UDDEN, J.A. - 1914 - Mechanical composition of clastic sediments. Bulletin Geological Society of America, Boulder, CO., 25(4):655-744.

UNIVERSIDADE ESTADUAL PAULISTA "JÚLIO DE MESQUITA FILHO” - 1984. Projeto Boa Vista - Relatório final. Rio Claro, SP, UNESP/PRÓ-MINÉRIO. v.I-II. Inédito.

VIEIRA, P.C. - 1982a - Geologia da Folha de Rio Capetinga. Revista do Instituto Geológico, São Paulo, 3(2):23-52.

- 1982b - Hipótese sobre a origem da Depressão Periférica Paulista. Revista do Instituto Geológico, São Paulo, 3(2):61-67.

Endereço dos autores:

- Ruy Osório de Freitas - Rua José do Patrocínio, 135 - Aclimação - 04108 - São Paulo, SP - Brasil

- Percy Corrêa Vieira - Instituto Geológico - SMA - Caixa Postal 8772 - 01051 - São Paulo, SP - Brasil.

- Sérgio Mezzalira - Rua Nanau, 77 - Água Fria - 02335 - São Paulo, SP - Brasil. 